\title{
Analysis of mass exchangers based on dimensionless numbers
}

\author{
N. Brandau \\ Volkswagen AG - Konzernforschung, Antriebe/Brennstoffzelle, Am Krainhop 5, 38550 Isenbüttel, Germany \\ S. Heinke $\mathbb{1}^{1}$, J. Koehler \\ Institut für Thermodynamik, Technische Universität Braunschweig, Hans-Sommer-Straße 5, 38106 Braunschweig, Germany
}

\begin{abstract}
A new model approach for an analytical calculation of a mass exchanger is presented in this work. By using three dimensionless numbers the mass transfer between two fluid flows can be calculated dependent on the flow geometry. A gas humidifier used for fuel cell application, which transfers water between two gas flows, is used as an example to illustrate the development of the operation characteristics for coflow, counterflow and crossflow. In this model approach the whole mass transfer process, governed by humidifier design and separator material properties, is described based on a single characteristic value, the effective mass transfer coefficient. The model provides a deeper understanding and prediction capability of the transfer processes which is helpful for mass exchanger designing and controlling. The coflow and counterflow case is validated by using a water permeable membrane as separator of wet air and dry air. Measurement data of a hollow fibre separator is used to validate the cross flow operated humidifier.
\end{abstract}

Keywords: mass transfer, mass exchanger, dimensionless numbers, operation characteristics, humidifier, fuel cell

\section{Introduction}

The laws of mass exchange play an important role in process engineering fields where the state of mixtures is changed. Often mass exchange is directly linked to heat exchange, for example when vaporization or condensation occurs. In such cases the process of mass transfer is not independent of the character of the simultaneous heat transfer. For practical applications heat transfer occurs somewhere between its theoretical limits of isothermal and adiabatic process conditions. For vaporization or condensation heat transfer even becomes the dominant influence on mass transfer. As a consequence, for practical handling of mass transfer processes heat transfer has to be accounted too. The same holds true for the phase equilibrium law's on boundary surfaces, the place where concentration gradients are formed.

Generally speaking, there are three resistances to be taken into account. One convective resistance in each fluid and one diffusive across the separator medium. For practical applications all resistances can be combined in one overall effective resistance. The effective heat transfer coefficient is used for heat transfer applications as is the effective mass transfer coefficient for mass transfer.

Today, the processes of heat exchange is sufficiently known for designing a heat exchanger which transfers heat from a hot fluid to a cold one $[1,2,3]$. For simple two-flow heat exchangers the analytical NTU-Method

\footnotetext{
${ }^{1}$ Corresponding author: Steffen Heinke, Institut für Thermodynamik, Technische Universität Braunschweig, Hans-SommerStraße 5, 38106 Braunschweig, Germany. Tel.: 0049531391 7894, fax: 0049531391 7814, e-mail: s.heinke@tu-bs.de

This is the post-print version of: Brandau, N.; Heinke, S.; Koehler, J.: Analysis of mass exchangers based on dimensionless numbers, International Journal of Heat and Mass Transfer, Volume 99, August 2016, Pages 261-267,

http://dx.doi.org/10.1016/j.ijheatmasstransfer.2016.03.080
} 
is a proper method for describing the operation characteristics. The NTU-Method is based on the three dimensionless numbers dimensionless temperature, number of transfer units (NTU) and heat capacity flow rate ratio. With approximate linearisation a mass exchanger should be described in a similar way owing to analogy between heat and mass transfer. To the best knowledge of the authors, this has never been published. Developing a similar method to describe a mass exchanger is content of this work. Like the overall heat transfer coefficient for heat exchange, the effective mass transfer coefficient represents all mass transfer resistances of the mass exchange process. With the example of a gas humidifier for fuel cell applications the presented analysis is validated.

Gas humidification plays an important role in fuel cell technology. Modern polymer-electrolyte-membrane (PEM) fuel cells require preconditioned process gases. In particular cases where the fuel cell is to be operated with air instead of pure oxygen, there is a risk of drying out the membrane within the fuel cell due to dry air. Air humidifiers are used to prevent this. During operation PEM fuel cells produce water which is carried out by the exhaust air flow. To humidify the fresh air a humidifier can be used. The air humidifier is a typical mass exchanger. It exchanges water from the fuel cell air exhaust to the fuel cell air inlet, as shown in figure 1. Usually the air humidity at the fuel cell inlet is controlled by opening and closing of a bypass flow path to the humidifier. This form of humidity control includes the actual state signal from a humidity

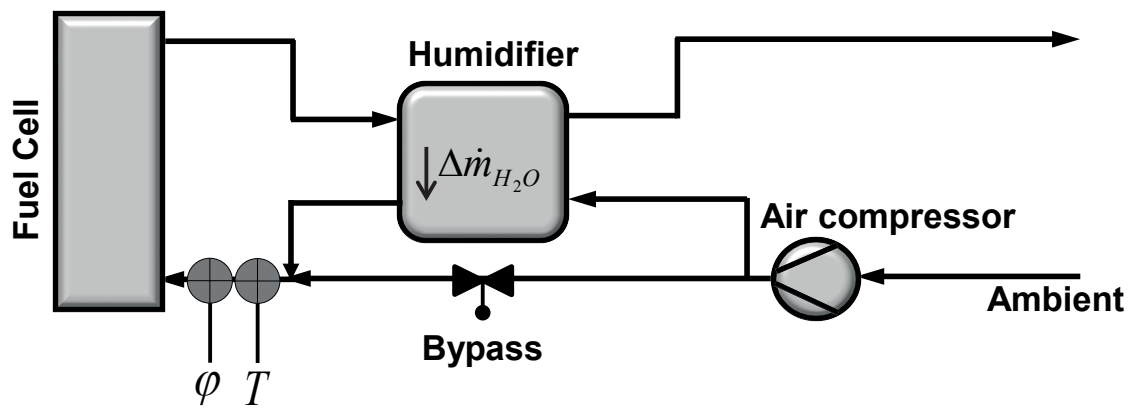

Figure 1: Air humidity control principle of a PEM fuel cell stack

sensor and a temperature sensor which are both integrated into the path downstream of the humidifier and upstream of the fuel cell. The operating characteristics of the humidifier change with

- fuel cell load and therefore product water formation,

- relative air humidity of the ambient,

- dry air mass flow rate provided by the air compressor

- dry air mass flow rate exhausting the fuel cell,

- air temperatures,

- temperature of the humidifier,

- effective transfer area of the humidifier,

- thickness and properties of the separator,

- operation pressures and

- pressure drop across the humidifier.

A dry air mass flow rate is defined as the rate of flow not including the water. The listed parameters may mutually influence each other, making a dynamic and precise control of the air humidity a challenging task. The following section presents an analytical model to describe the mass transfer within such a humidifier 
which permits an analytical calculation of the relative humidity at the air-side inlet of the fuel cell. This analytical model of the humidifier might provide options to replace some or even all of the gas humidification sensors. The use of a predictive, model-based pre-control system for gas humidification promises improved dynamic behaviour of the humidification control of PEM fuel cell systems.

\section{Model of mass exchanger}

Mass transfer processes are ubiquitous in nature and play an important role in various engineering processes in which the state of a mixture of constituents is changed. In particular, these are physical separation processes and numerous chemical reactions. A general challenge of mass transport is that the substance of interest can be unevenly distributed in the carrier medium. This uneven distribution is described by concentration gradients, whereby the gradients themselves are the driving forces for the mass transport.

\subsection{General equations}

According to Fick's Law [4], the diffusive molar flux can be written as

$$
j_{i}=-D \cdot \frac{d c_{i}}{d y}
$$

In this equation $D$ is the diffusion coefficient and $\frac{d c_{i}}{d y}$ the molar concentration gradient of component $i$. The molar concentration of the component $c_{i}$ is defined as

$$
c_{i}=\frac{\dot{n}_{i}}{\dot{V}},
$$

where $\dot{V}$ denotes the total volume flow rate.

A separator separates two molar flow rates $\dot{n}_{1}$ and $\dot{n}_{2}$ from each other. These flow rates consist of binary mixtures with the two components $a$ and $b$. The two molar flow rates can be written as

$$
\begin{aligned}
& \dot{n}_{1}=\dot{n}_{1 a}+\dot{n}_{1 b}=\dot{V}_{1} \cdot\left(c_{1 a}+c_{1 b}\right) \text { and } \\
& \dot{n}_{2}=\dot{n}_{2 a}+\dot{n}_{2 b}=\dot{V}_{2} \cdot\left(c_{2 a}+c_{2 b}\right) .
\end{aligned}
$$

The separator is permeable for the component $b$ and impermeable for the component $a$, as seen in figure 2 . Only $\dot{n}_{b}$ varies along the transfer area within a mass exchanger. Figure 3 shows a general sketch of a mass

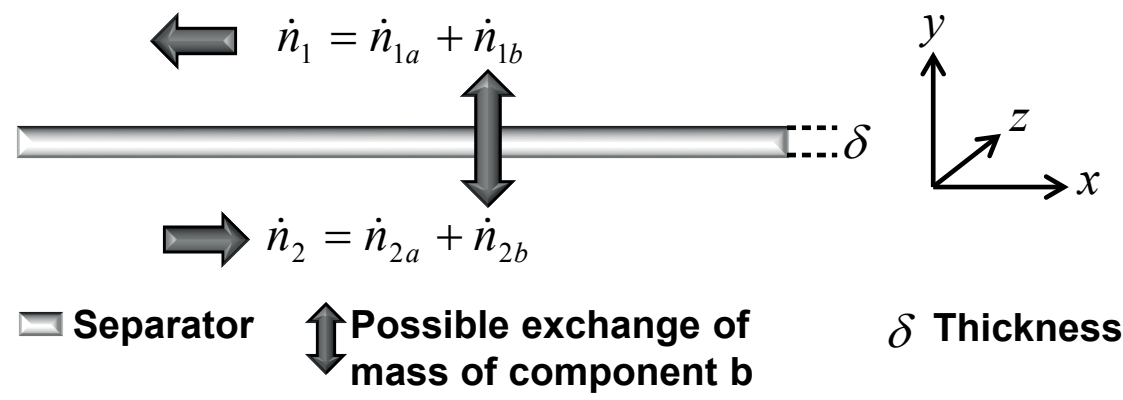

Figure 2: Two molar flows separated by a separator

exchanger. Variables with one prime denote the inlet and those with a double prime denote the outlet of the mass exchanger. The requirement that the component $\dot{n}_{a}$ remains constant yields

$$
\begin{aligned}
& \dot{n}_{1 a}^{\prime \prime}=\dot{n}_{1 a}^{\prime} \text { and } \\
& \dot{n}_{2 a}^{\prime \prime}=\dot{n}_{2 a}^{\prime} .
\end{aligned}
$$




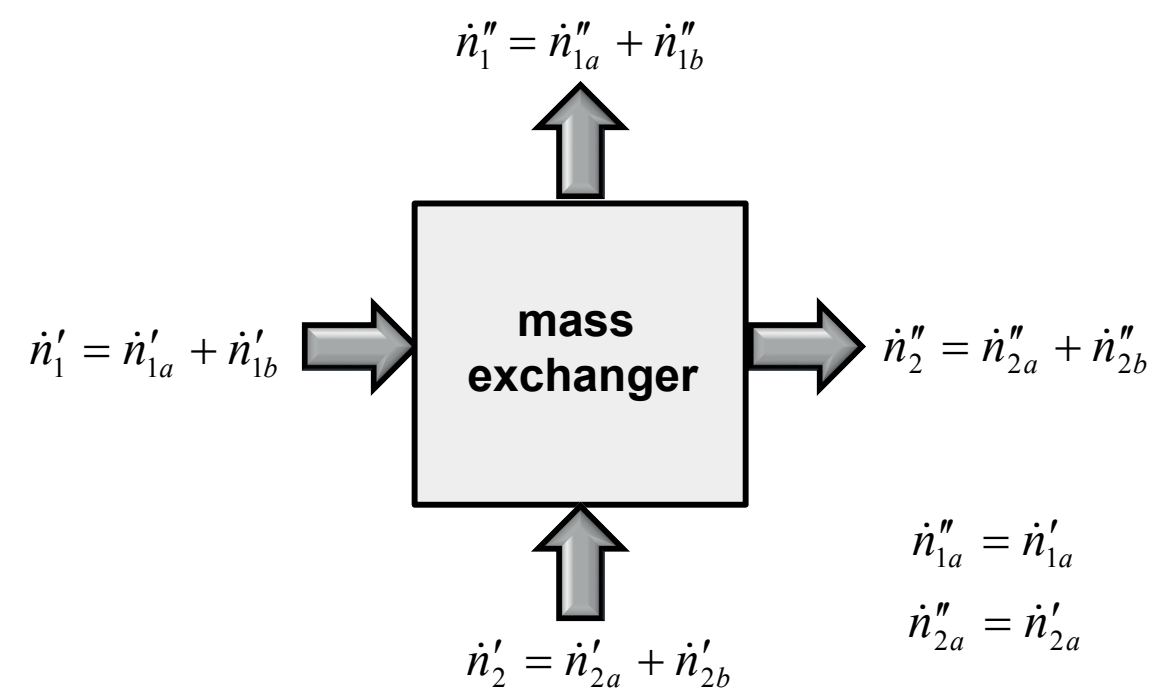

Figure 3: Inlet and outlet flow rates of a mass exchanger

The molar flow rate $\Delta \dot{n}_{b}$ of the component $b$ transferred by the mass exchanger can be calculated by forming balances for the two molar flow rates $\dot{n}_{1}$ and $\dot{n}_{2}$.

$$
\begin{aligned}
& \Delta \dot{n}_{1 b}=\dot{n}_{1}^{\prime}-\dot{n}_{1}^{\prime \prime}=\left(\dot{n}_{1 a}^{\prime}+\dot{n}_{1 b}^{\prime}\right)-\left(\dot{n}_{1 a}^{\prime \prime}+\dot{n}_{1 b}^{\prime \prime}\right)=\dot{n}_{1 b}^{\prime}-\dot{n}_{1 b}^{\prime \prime} \\
& \Delta \dot{n}_{2 b}=\dot{n}_{2}^{\prime}-\dot{n}_{2}^{\prime \prime}=\left(\dot{n}_{2 a}^{\prime}+\dot{n}_{2 b}^{\prime}\right)-\left(\dot{n}_{2 a}^{\prime \prime}+\dot{n}_{2 b}^{\prime \prime}\right)=\dot{n}_{2 b}^{\prime}-\dot{n}_{2 b}^{\prime \prime}
\end{aligned}
$$

The transfer of mass between $\dot{n}_{1 b}$ and $\dot{n}_{2 b}$ causes one of the two flows to decrease and the other consequently to increase. Thus, the relationship between the change in both flows is given by

$$
\Delta \dot{n}_{1 b}=-\Delta \dot{n}_{2 b}=\Delta \dot{n}_{b}
$$

Based on the assumption that the molar flow rates $\dot{n}_{1}$ and $\dot{n}_{2}$ as well as the volume flow rates $\dot{V}_{1}$ and $\dot{V}_{2}$ remain almost constant, i.e. $\dot{n}_{1}^{\prime} \approx \dot{n}_{1}^{\prime \prime}=\dot{n}_{1 a}+\dot{n}_{1 b} \gg \Delta \dot{n}_{b}$, the transferred molar flow rate can be calculated for (nearly) isothermal and isobaric conditions using equations $2,3,4,7$ and 8.

$$
\begin{aligned}
\Delta \dot{n}_{b} & =\dot{n}_{1 b}^{\prime}-\dot{n}_{1 b}^{\prime \prime}=\frac{c_{1 b}^{\prime}}{c_{1 a}^{\prime}} \cdot \dot{n}_{1 a}^{\prime}-\frac{c_{1 b}^{\prime \prime}}{c_{1 a}^{\prime \prime}} \cdot \dot{n}_{1 a}^{\prime \prime} \\
& \approx \frac{c_{1 b}^{\prime}}{c_{1 a}^{\prime}} \cdot \dot{n}_{1 a}^{\prime}-\frac{c_{1 b}^{\prime \prime}}{c_{1 a}^{\prime}} \cdot \dot{n}_{1 a}^{\prime}=\left(c_{1 b}^{\prime}-c_{1 b}^{\prime \prime}\right) \frac{\dot{n}_{1 a}^{\prime}}{c_{1 a}^{\prime}} \\
-\Delta \dot{n}_{b} & =\dot{n}_{2 b}^{\prime}-\dot{n}_{2 b}^{\prime \prime}=\frac{c_{2 b}^{\prime}}{c_{2 a}^{\prime}} \cdot \dot{n}_{2 a}^{\prime}-\frac{c_{2 b}^{\prime \prime}}{c_{2 a}^{\prime \prime}} \cdot \dot{n}_{2 a}^{\prime \prime} \\
& \approx \frac{c_{2 b}^{\prime}}{c_{2 a}^{\prime}} \cdot \dot{n}_{2 a}^{\prime}-\frac{c_{2 b}^{\prime \prime}}{c_{2 a}^{\prime}} \cdot \dot{n}_{2 a}^{\prime}=\left(c_{2 b}^{\prime}-c_{2 b}^{\prime \prime}\right) \frac{\dot{n}_{2 a}^{\prime}}{c_{2 a}^{\prime}}
\end{aligned}
$$

To calculate the infinitesimal mass transfer $d \dot{n}_{b}$, an infinitesimal area element $d A$ of the separator is considered, as can be seen in figure 4 . The transport of mass $d \dot{n}_{b}$ through the area element $d A$ can be described by

$$
d \dot{n}_{b}=d c_{1 b} \cdot \frac{\dot{n}_{1 a}^{\prime}}{c_{1 a}^{\prime}}
$$

for the infinitesimal concentration change of $\dot{n}_{1}$,

$$
d \dot{n}_{b}=-d c_{2 b} \cdot \frac{\dot{n}_{2 a}^{\prime}}{c_{2 a}^{\prime}}
$$




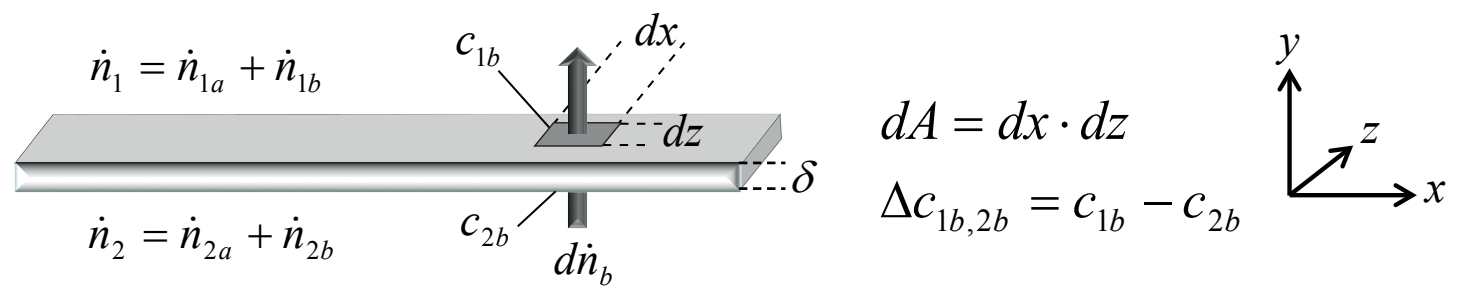

\section{$\exists$ Separator $\uparrow$ Exchange of mass of $\delta$ Thickness component b}

Figure 4: Infinitesimal area element of the separator

for the infinitesimal concentration change of $\dot{n}_{2}$, and

$$
d \dot{n}_{b}=-D \frac{\Delta c_{1 b, 2 b}}{\delta} \cdot d x \cdot d z \text { with } \Delta c_{1 b, 2 b}=c_{1 b}-c_{2 b}
$$

for the transferred molar flow rate across the separator (permeation) from $\dot{n}_{2}$ to $\dot{n}_{1}$. The mass transfer from fluid 1 to fluid 2 is governed by three different physical effects, as shown in figure 5:

1. Convective mass transfer in the fluid phases from the bulk flow to the surface.

2. Phase equilibrium between the fluid phase and the solid phase at the two surfaces, described by Henry's Law.

3. Diffusion through the solid phase, described by Fick's Law.

For the sake of simplicity, these three effects are all taken into account by using an effective diffusion coefficient $D_{\text {eff }}$ in order to calculate the mass transfer from one fluid to the other. Accordingly, an effective

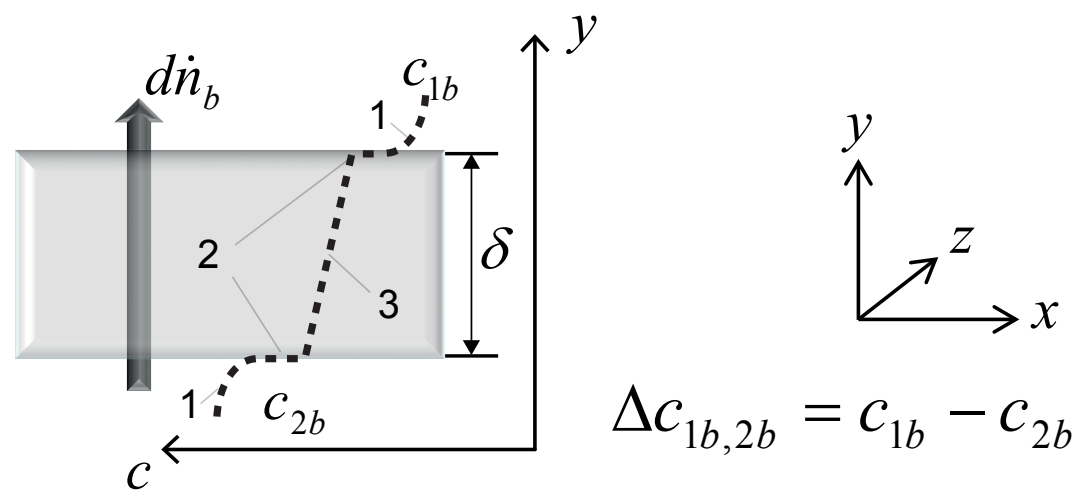

\section{Separator $\uparrow$ Exchange of mass of $\delta$ Thickness component b}

Figure 5: Local concentration distribution across separator

mass transfer coefficient [5] is used.

$$
\beta_{e f f}=\frac{D_{e f f}}{\delta}
$$

Eliminating the infinitesimal transfer mass flow rate $d \dot{n}_{b}$ by equating equations 12 and 13 to equation 14 
yields two equations for the infinitesimal concentration change of the molar flow rates $\dot{n}_{1 b}$ and $\dot{n}_{2 b}$.

$$
\begin{aligned}
& d c_{1 b}=-\beta_{e f f} \cdot\left(c_{1 b}-c_{2 b}\right) \cdot \frac{c_{1 a}^{\prime}}{\dot{n}_{1 a}^{\prime}} \cdot d x \cdot d z \\
& d c_{2 b}=\beta_{e f f} \cdot\left(c_{1 b}-c_{2 b}\right) \cdot \frac{c_{2 a}^{\prime}}{\dot{n}_{2 a}^{\prime}} \cdot d x \cdot d z
\end{aligned}
$$

The infinitesimal concentration changes $d c_{1 b}$ and $-d c_{2 b}$ depend on the direction of the concentration change across the area of the separator. At this point, a distinction regarding the flow direction of $\dot{n}_{2}$ and $\dot{n}_{1}$ is necessary. A crossflow will cause a concentration change with $d x$ and $d z$. The derivation for the cross flow will not be discussed here. It follows the same steps as the derivation for the coflow and counterflow cases similar as that for a crossflow heat exchanger [2]. For counterflow and coflow, equation 17 is subtracted from equation 16 to arrive at a differential equation for the concentration difference $\Delta c_{1 b, 2 b}=c_{1 b}-c_{2 b}$.

$$
d\left(c_{1 b}-c_{2 b}\right)=\left(-\frac{c_{1 a}^{\prime}}{\dot{n}_{1 a}^{\prime}}-\frac{c_{2 a}^{\prime}}{\dot{n}_{2 a}^{\prime}}\right) \cdot \beta_{e f f} \cdot\left(c_{1 b}-c_{2 b}\right) \cdot d A
$$

Algebraic manipulation yields

$$
\frac{d\left(c_{1 b}-c_{2 b}\right)}{c_{1 b}-c_{2 b}}=\left(-\frac{c_{1 a}^{\prime}}{\dot{n}_{1 a}^{\prime}}-\frac{c_{2 a}^{\prime}}{\dot{n}_{2 a}^{\prime}}\right) \cdot \beta_{e f f} \cdot d A .
$$

Integrating this equation over the whole mass transfer area $A$ yields the relationship between the area of the mass exchanger, the volume flow rates with $\frac{1}{\dot{V}_{1}^{\prime}}=\frac{c_{1 a}^{\prime}}{\grave{n}_{1 a}^{\prime}}, \frac{1}{\dot{V}_{2}^{\prime}}=\frac{c_{2 a}^{\prime}}{\dot{n}_{2 a}^{\prime}}$ and the concentration differences at the inlet and outlet of the mass exchanger. With respect to the relative flow direction of $\dot{n}_{2}$ to $\dot{n}_{1}$, a counterflow and coflow have to be treated separately.

\subsection{Counterflow}

Figure 6 sketches the concentration distribution curves and the integration limits for counterflow mass exchangers.

The two volume flow rates $\dot{V}_{1}^{\prime}$ and $\dot{V}_{2}^{\prime}$ have opposite directions. Hence, $\dot{V}_{1}^{\prime}$ has an negative sign and equation 19 becomes

$$
\int_{0: c_{1 b}^{\prime \prime}-c_{2 b}^{\prime}}^{A: c_{1 b}^{\prime}-c_{2 b}^{\prime \prime}} \frac{d\left(c_{1 b}-c_{2 b}\right)}{c_{1 b}-c_{2 b}}=\int_{0}^{A}\left(-\frac{1}{-\dot{V}_{1}^{\prime}}-\frac{1}{\dot{V}_{2}^{\prime}}\right) \cdot \beta_{e f f} \cdot d A
$$

Integration yields

$$
\ln \left(\frac{c_{1 b}^{\prime}-c_{2 b}^{\prime \prime}}{c_{1 b}^{\prime \prime}-c_{2 b}^{\prime}}\right)=\frac{\beta_{e f f} \cdot A}{\dot{V}_{1}^{\prime}}-\frac{\beta_{e f f} \cdot A}{\dot{V}_{2}^{\prime}}
$$

\subsection{Coflow}

Figure 7 sketches the concentration curves and the integration limits for coflow mass exchangers. Here the two volume flow rates $\dot{V}_{1}^{\prime}$ and $\dot{V}_{2}^{\prime}$ have the same direction and equation 19 becomes

$$
\int_{0: c_{1 b}^{\prime}-c_{2 b}^{\prime}}^{A: c_{1 b}^{\prime \prime}-c_{2 b}^{\prime \prime}} \frac{d\left(c_{1 b}-c_{2 b}\right)}{c_{1 b}-c_{2 b}}=\int_{0}^{A}-\left(\frac{1}{\dot{V}_{1}^{\prime}}+\frac{1}{\dot{V}_{2}^{\prime}}\right) \cdot \beta_{e f f} \cdot d A .
$$

Integration yields

$$
\ln \left(\frac{c_{1 b}^{\prime \prime}-c_{2 b}^{\prime \prime}}{c_{1 b}^{\prime}-c_{2 b}^{\prime}}\right)=-\left(\frac{\beta_{e f f} \cdot A}{\dot{V}_{1}^{\prime}}+\frac{\beta_{e f f} \cdot A}{\dot{V}_{2}^{\prime}}\right)
$$




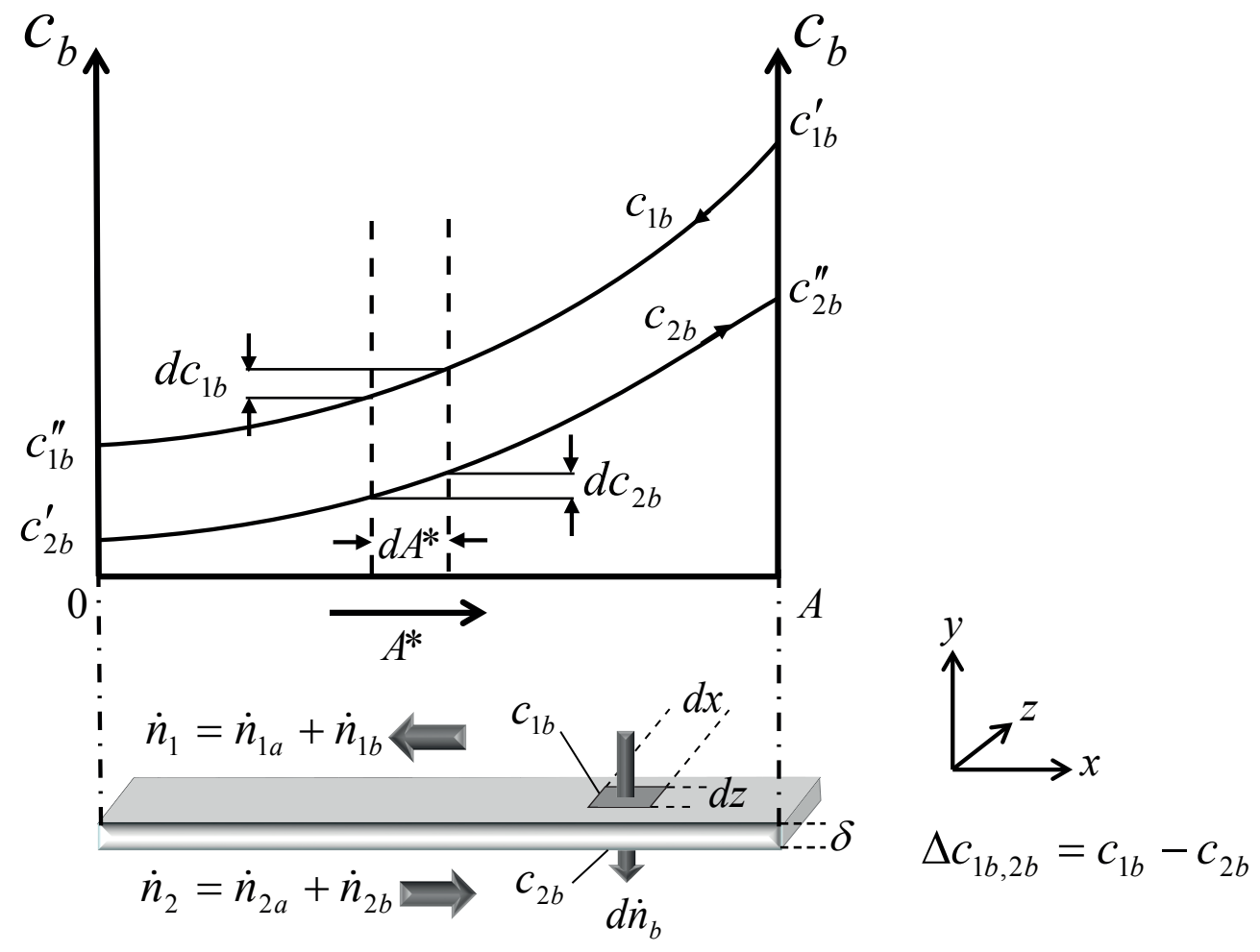

\section{Separator $\uparrow$ Exchange of mass of $\delta$ Thickness component $b$}

Figure 6: Mass transfer and concentration distribution curves for counterflow

\section{Dimensionless numbers and operation characteristics}

\subsection{Dimensionless numbers of mass transfer}

According to the Buckingham $\Pi$ theory, $n$ dimensioned physical parameters can be reduced to $n-r$ dimensionless numbers, if $r$ basic physical units are needed to completely describe the physical problem [6]. In the present case $n=5$ dimensioned physical parameters are important,

$$
\Delta \dot{n}_{b}\left[\frac{\mathrm{mol}}{\mathrm{s}}\right] ; c_{1 b}^{\prime}-c_{2 b}^{\prime}\left[\frac{\mathrm{mol}}{\mathrm{m}^{3}}\right] ; \beta_{e f f} \cdot A\left[\frac{\mathrm{m}}{\mathrm{s}} \cdot \mathrm{m}^{2}=\frac{\mathrm{m}^{3}}{\mathrm{~s}}\right] ; \dot{V}_{1}^{\prime}\left[\frac{\mathrm{m}^{3}}{\mathrm{~s}}\right] ; \dot{V}_{2}^{\prime}\left[\frac{\mathrm{m}^{3}}{\mathrm{~s}}\right] .
$$

with two basic physical units $\frac{\mathrm{mol}}{\mathrm{s}}$ and $\frac{\mathrm{mol}}{\mathrm{m}^{3}}$ from which the other three dimensioned physical parameters can be derived. Hence, three dimensionless numbers for the mass transfer can be found.

\section{The dimensionless concentration change}

$$
\eta_{\Delta 1}=\frac{\Delta \dot{n}_{b}}{\dot{V}_{1}^{\prime} \cdot\left(c_{1 b}^{\prime}-c_{2 b}^{\prime}\right)}=\frac{\left(c_{1 b}^{\prime}-c_{1 b}^{\prime \prime}\right) \cdot \frac{\dot{n}_{1 a}^{\prime}}{c_{1 a}^{\prime}}}{\dot{V}_{1}^{\prime} \cdot\left(c_{1 b}^{\prime}-c_{2 b}^{\prime}\right)}=\frac{c_{1 b}^{\prime}-c_{1 b}^{\prime \prime}}{c_{1 b}^{\prime}-c_{2 b}^{\prime}}
$$

$\left(\eta_{\Delta 1}\right.$ can also be seen as efficiency)

The dimensionless transfer capacity NTU (Number of Transfer Units)

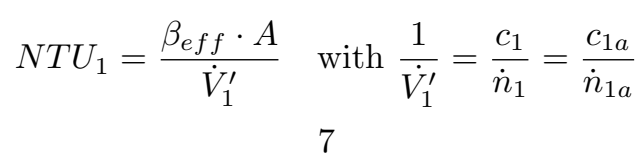




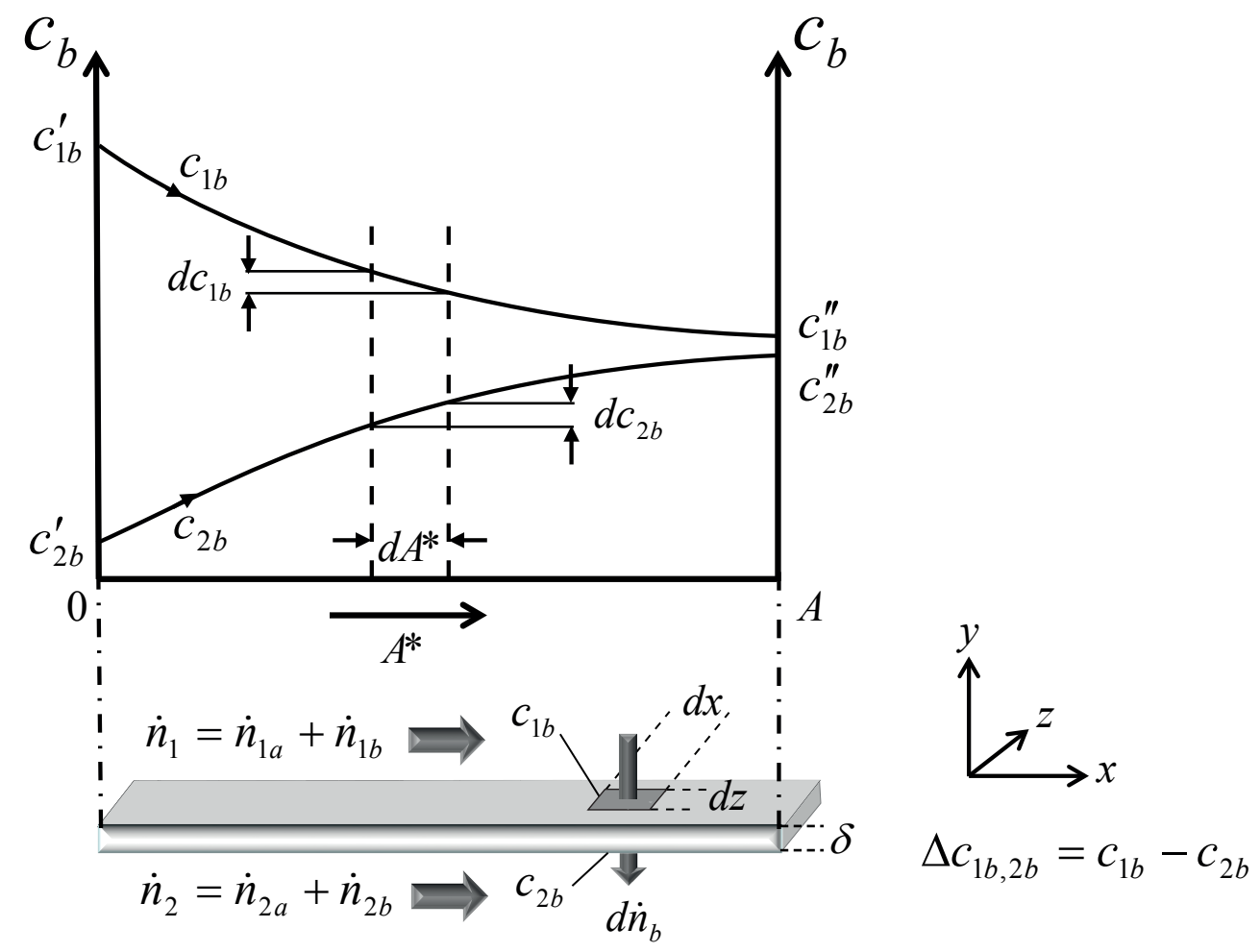

\section{$\exists$ Separator $\uparrow$ Exchange of mass of $\delta$ Thickness component b}

Figure 7: Mass transfer and concentration distribution curves for coflow

The dimensionless ratio of the volume flow rates (Brandau Number)

$$
B r_{1}=\frac{\dot{V}_{1}^{\prime}}{\dot{V}_{2}^{\prime}}
$$

$\eta_{\Delta 1}$ represents the actual transmitted flow rate of component $b$ in gas flow 1 relative to the maximum possible transmitted flow rate of component $b$.

The dimensionless numbers also can be expressed based on the parameters of the second mass flow:

$$
\begin{gathered}
\eta_{\Delta 2}=\frac{\dot{V}_{1}^{\prime}}{\dot{V}_{2}^{\prime}} \cdot \eta_{\Delta 1}=\frac{N T U_{2}}{N T U_{1}} \cdot \eta_{\Delta 1}=B r_{1} \cdot \eta_{\Delta 1}=\frac{c_{2 b}^{\prime \prime}-c_{2 b}^{\prime}}{c_{1 b}^{\prime}-c_{2 b}^{\prime}} \\
N T U_{2}=\frac{\beta_{e f f} \cdot A}{\dot{V}_{2}^{\prime}} \\
B r_{2}=\frac{\dot{V}_{2}^{\prime}}{\dot{V}_{1}^{\prime}}=\frac{N T U_{1}}{N T U_{2}}=\frac{1}{B r_{1}}
\end{gathered}
$$

Furthermore, the three dimensionless numbers can also be expressed in terms of the partial pressure $p_{i}$, the temperature $T$, the partial density $\rho_{i}$ and the mass flow rate $m_{i}$ of the component $i$. For ideal gases the following relations are valid:

$$
p_{i} \cdot V=n_{i} \cdot R \cdot T \Rightarrow c_{i}=\frac{p_{i}}{R \cdot T}=\frac{n_{i}}{V} ; \rho_{i}=\frac{p_{i}}{R_{i} \cdot T}=\frac{m_{i}}{V}
$$

With $\dot{V}=\frac{\dot{m}_{i}}{\rho_{i}}$ and Dalton's law $p_{\text {Gas }}=\sum_{i} p_{i}$ it follows: 


\section{Dimensionless concentration change}

$$
\eta_{\Delta 1}=\frac{\frac{\Delta \dot{m}_{1 b}}{M_{b}}}{\dot{V}_{1}^{\prime} \cdot\left[\frac{p_{1 b}^{\prime}}{R \cdot T_{1}^{\prime}}-\frac{p_{2 b}^{\prime}}{R \cdot T_{2}^{\prime}}\right]}=\frac{\left[\frac{p_{1 b}^{\prime}}{T_{1}^{\prime}}-\frac{p_{1 b}^{\prime \prime}}{T_{1}^{\prime \prime}}\right] \cdot \frac{\dot{V}_{1}^{\prime}}{R}}{\frac{\dot{V}_{1}^{\prime}}{R} \cdot\left[\frac{p_{1 b}^{\prime}}{T_{1}^{\prime}}-\frac{p_{2 b}^{\prime}}{T_{2}^{\prime}}\right]}=\frac{\left(\frac{p_{1 b}^{\prime}}{T_{1}^{\prime}}\right)-\left(\frac{p_{1 b}^{\prime \prime}}{T_{1}^{\prime \prime}}\right)}{\left(\frac{p_{1 b}^{\prime}}{T_{1}^{\prime}}\right)-\left(\frac{p_{2 b}^{\prime}}{T_{2}^{\prime}}\right)}
$$

with

$$
\begin{gathered}
\left|T_{1}^{\prime}-T_{1}^{\prime \prime}\right| \ll \frac{T_{1}^{\prime}+T_{1}^{\prime \prime}}{2},\left|T_{1}^{\prime}-T_{2}^{\prime}\right| \ll \frac{T_{1}^{\prime}+T_{2}^{\prime}}{2} \text { and } \\
\left|p_{\mathrm{Gas}, 1}^{\prime}-p_{\mathrm{Gas}, 1}^{\prime \prime}\right| \ll \frac{p_{\mathrm{Gas}, 1}^{\prime}+p_{\mathrm{Gas}, 1}^{\prime \prime}}{2},\left|p_{\mathrm{Gas}, 2}^{\prime}-p_{\mathrm{Gas}, 2}^{\prime \prime}\right| \ll \frac{p_{\mathrm{Gas}, 2}^{\prime}+p_{\mathrm{Gas}, 2}^{\prime \prime}}{2}
\end{gathered}
$$

(Regarding constraints for equation 10 and 11).

\section{Dimensionless transfer capacity NTU (Number of Transfer Units)}

$$
N T U_{1}=\frac{\beta_{e f f} \cdot A}{\dot{V}_{1}^{\prime}}=\frac{\beta_{e f f} \cdot A}{\frac{\dot{m}_{1 a}^{\prime}}{\rho_{1 a}^{\prime}}}=\frac{\beta_{e f f} \cdot A \cdot \rho_{1 a}^{\prime}}{\dot{m}_{1 a}^{\prime}}
$$

Dimensionless ratio of the volume flow rates (Brandau Number)

$$
B r_{1}=\frac{\dot{V}_{1}^{\prime}}{\dot{V}_{2}^{\prime}}=\frac{\left(\frac{\dot{m}_{1 a}^{\prime}}{\rho_{1 a}^{\prime}}\right)}{\left(\frac{\dot{m}_{2 a}^{\prime}}{\rho_{2 a}^{\prime}}\right)}
$$

\subsection{Operation characteristics of mass exchangers}

The relationship between the three aforementioned dimensionless numbers $\eta_{\Delta 1}, N T U_{1}$ and $B r_{1}$ can be used to analytically describe the operation characteristics of a mass exchanger.

After some algebraic manipulations of equation 21 in order to introduce the three dimensionless numbers, the operation characteristics for counterflow mass transfer across a separator can be written as

$$
\ln \left(\frac{1-\eta_{\Delta 1}}{1-B r_{1} \cdot \eta_{\Delta 1}}\right)=N T U_{1} \cdot\left(B r_{1}-1\right)
$$

Using equation 23 yields the coflow relation

$$
\ln \left[1-\eta_{\Delta 1} \cdot\left(1+B r_{1}\right)\right]=N T U_{1} \cdot\left(B r_{1}+1\right)
$$

For crossflow across the separator area, the following results represent the main cases, as seen in figure 8 . The detailed derivation is analogous to that of a crossflow heat exchanger [2]. The operation characteristics

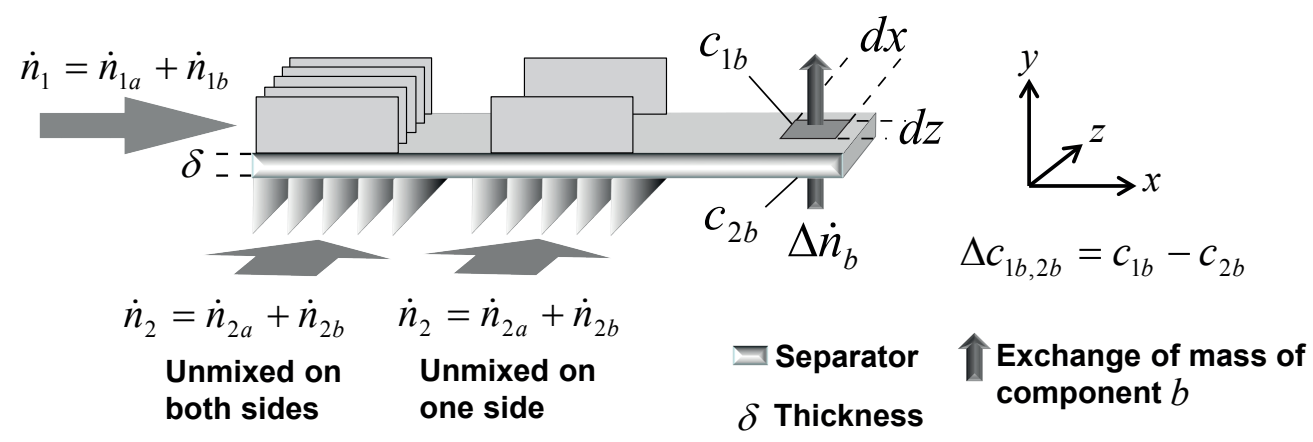

Figure 8: Two mostly used cases of molar flow rates with a pure crossflow operation of a mass exchanger 


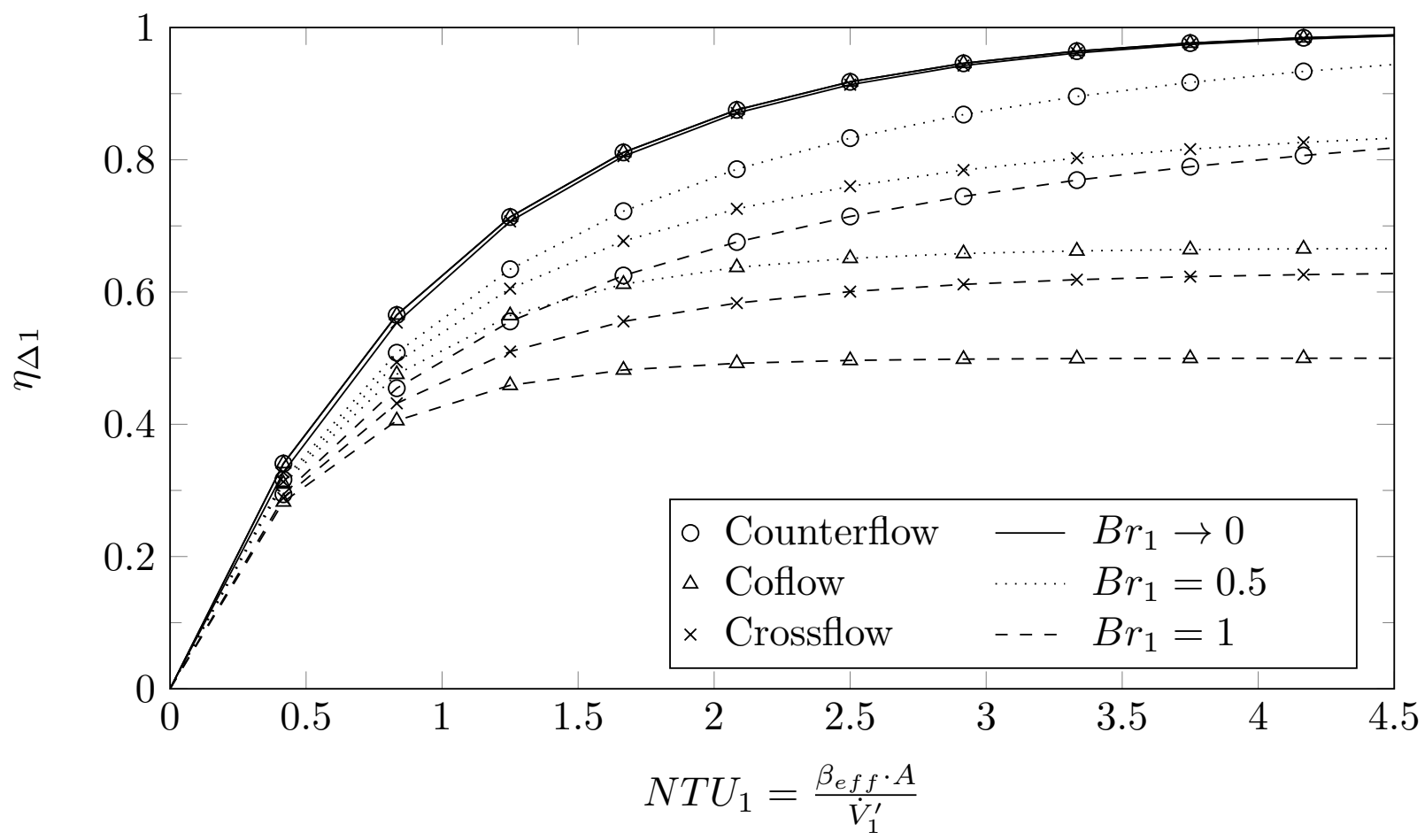

Figure 9: Operation characteristics for crossflow, counterflow and coflow of a mass exchanger for different $B r_{1}$ values

are for Crossflow unmixed on both sides

$$
\eta_{\Delta 1}=\frac{1}{B r_{1} \cdot N T U_{1}} \cdot \sum_{m=0}^{\infty}\left\{\left[1-e^{-N T U_{1}} \cdot \sum_{j=0}^{m} \frac{N T U_{i}^{j}}{j !}\right] \cdot\left[1-e^{-B r_{1} \cdot N T U_{1}} \cdot \sum_{j=0}^{m} \frac{\left(B r_{1} \cdot N T U_{1}\right)^{j}}{j !}\right]\right\}
$$

and for crossflow mixed on one side

$$
\eta_{\Delta 1}=1-e^{-\frac{1}{B r_{1}} \cdot\left(1-e^{-B r_{1} \cdot N T U_{1}}\right)} .
$$

Table 1 summarizes the operation characteristics for counter-, co-, and crossflow conditions of a mass exchanger as described above.

The graphical representation of relations given in table 1 can be seen in figure 9 . The dimensionless concentration change $\eta_{\Delta 1}$ is plotted over the number of transfer units $N T U_{1}$ for varying air flow ratio $B r_{1}$. It can be seen that the concentration change $\eta_{\Delta 1}$ is virtually independent on the flow configuration, if $B r_{1}$ approaches zero. For $B r \neq 0$ the maximum concentration change and thus the maximum efficiency of a mass exchanger is achieved with a counterflow configuration.

Use of equation 24 arrives to the transferred molar flow rate.

\section{Model validation}

In this section, the previously developed model is validated based on experimental data of a fuel cell gas humidifier used as mass exchanger. A planar membrane humidifier represents the coflow and counterflow validation. The cross flow validation is shown by using experimental data of a hollow fibre humidifier. 


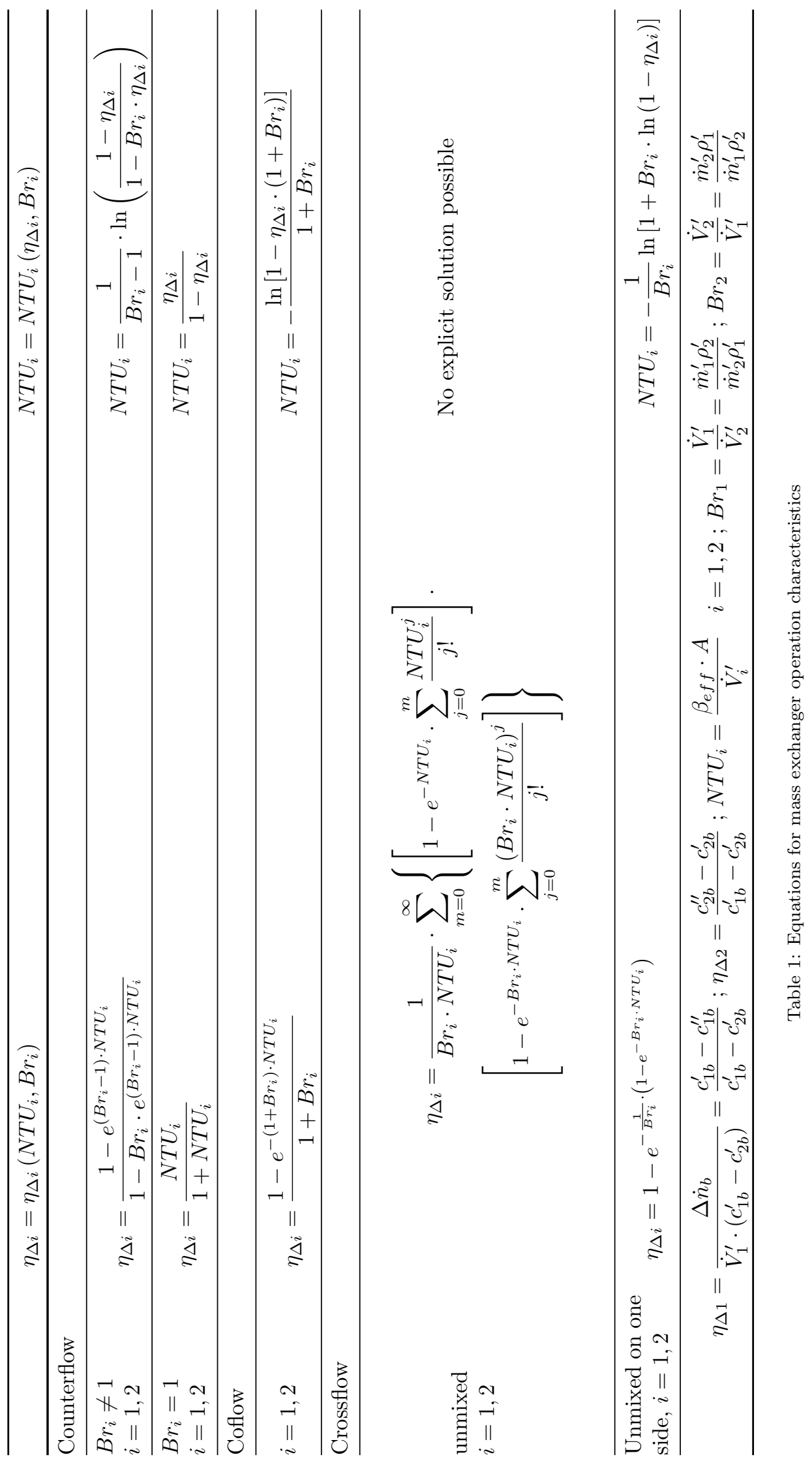




\begin{tabular}{ll}
\hline Wet gas stream \\
\hline$\dot{m}^{\prime}$ & $3.8 \times 10^{-6} \mathrm{~kg} / \mathrm{s}$ to $4.3 \times 10^{-5} \mathrm{~kg} / \mathrm{s}$ \\
$p^{\prime}$ & $2 \mathrm{bar}$ \\
$T^{\prime}$ & $64{ }^{\circ} \mathrm{C}$ \\
$\varphi^{\prime}$ & $84 \%$ \\
\hline Dry gas stream & \\
\hline$\dot{m}^{\prime}$ & $3.8 \times 10^{-6} \mathrm{~kg} / \mathrm{s}$ to $4.3 \times 10^{-4} \mathrm{~kg} / \mathrm{s}$ \\
$p^{\prime}$ & $2 \mathrm{bar}$ \\
$T^{\prime}$ & $64{ }^{\circ} \mathrm{C}$ \\
$\varphi^{\prime}$ & $2 \%$ \\
\hline Humidifier & \\
\hline$T$ & $66^{\circ} \mathrm{C}$ \\
\hline
\end{tabular}

Table 2: Boundary conditions for the experimental validation of the model

\subsection{Effective mass transfer coefficient}

As already mentioned, the mass transfer coefficients of humidifiers are effective coefficients, describing the overall mass transfer process of water within the humidifier (see figure 5). That means the effective mass transfer coefficient takes into account humidifier design factors like flow field geometry, used diffusion layer, separator properties and channel design. The effective mass transfer coefficient depends on laminar or turbulent flow within the humidifier as well as on temperature and humidity driven diffusion. For the following model validation in each case the effective mass transfer coefficient was determined by a simple correlation depending on Reynolds numbers of both air flows assuming laminar flow as well as a linear dependence on the relative humidity $\varphi$ of the wet air stream $[7,8]$.

$$
\beta_{e f f}=c \cdot \varphi+m
$$

The coefficients $c$ and $m$ are functions of Reynolds numbers and membrane properties. Measured relations between the effective mass transfer coefficient and relative humidity are provided in [9].

\subsection{Experimental setup}

For the experimental investigation of the aforementioned humidifiers gas inlet conditions for pressure, relative humidity and temperature of the wet and dry gas stream are kept constant. Gas mass flow rates are varied for both streams in order to achieve desired $B r$ and $N T U$ values. The boundary conditions are summarized in table 2.

For each flow configuration pressure, temperature and relative humidity are measured of both gas streams at the inlet and outlet. Based on the relation for $\beta_{\text {eff }}$ (see section 4.1) and the calculation of the humid gas density as a function of pressure, temperature and humidity [10] the three dimensionless numbers $B r, \eta_{\Delta}$ and $N T U$ can be calculated. The locations of the measurement points are depicted in figure 10 using the example of the counterflow humidifier. For the other flow configurations the experimental setup is analogous. Table 3 lists the sensors used with their measuring range and accuracy. Results of the experiments and validation of the developed model are presented in the following sections.

\subsection{Counterflow}

The setup of measurement for a mass exchanger operated in counterflow in general is shown in figure 11. Between an air flow and a humidified air flow water is exchanged by a water permeable membrane. The measured operation characteristics for different NTU values including the measurement uncertainties shows figure 12 in comparison to the prediction based on the relations provided by table 1 . 


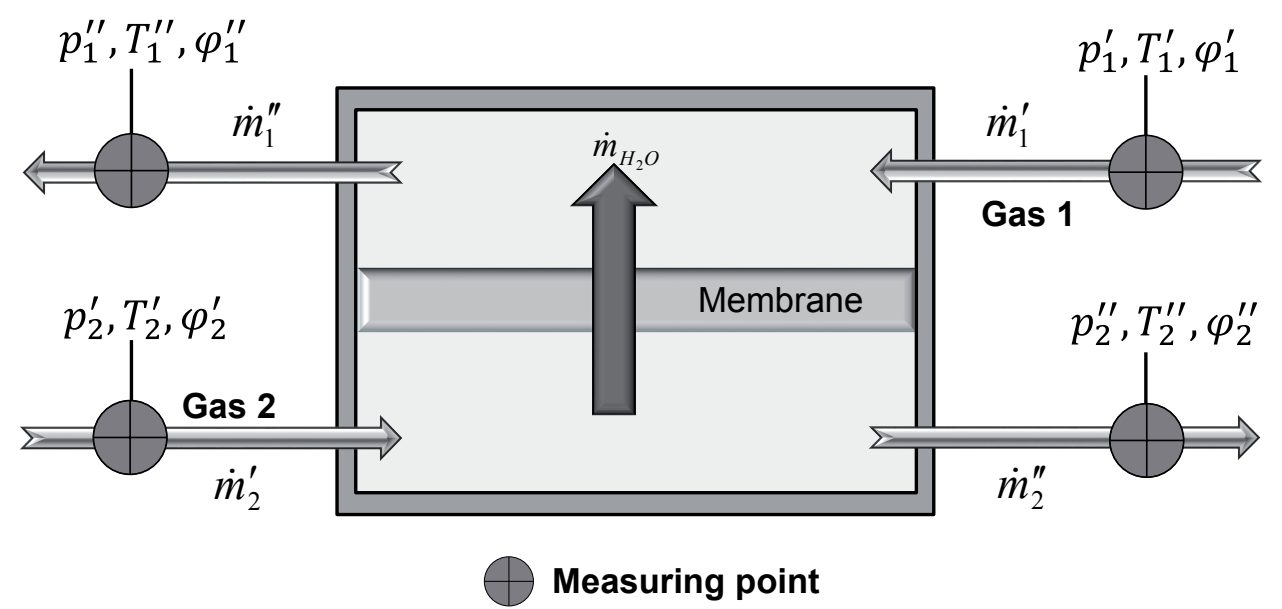

Figure 10: Experimental setup of the counterflow humidifier with the measurement locations at the inlets and outlets of both gas streams

\begin{tabular}{|c|c|c|c|}
\hline Sensor & Type & Measuring range & Accuracy \\
\hline Humidity & $\begin{array}{l}\text { Rotronic } \\
\text { HYGROCLIP IM } 3\end{array}$ & $0 \%-100 \%$ & $\pm 2.8 \% \mathrm{FS}$ \\
\hline Temperature & $\begin{array}{l}\text { Rotronic } \\
\text { HYGROCLIP IM } 3\end{array}$ & $40^{\circ} \mathrm{C}-125^{\circ} \mathrm{C}$ & $\pm 0.3 \% \mathrm{FS}$ \\
\hline Pressure & $\begin{array}{l}\text { i2s } \\
\text { XKP } 1290\end{array}$ & 0 bar -4 bar & $\pm 0.5 \% \mathrm{FS}$ \\
\hline Mass flow rate & $\begin{array}{l}\text { Bronkhorst } \\
\text { EL-Flow F201AC }\end{array}$ & $0 \mathrm{~L} / \mathrm{min}-20 \mathrm{~L} / \mathrm{min}$ & $\pm 0.5 \% \mathrm{FS}$ \\
\hline
\end{tabular}

Table 3: Sensors used for the experimental measurements

\subsection{Coflow}

Figure 13 shows the setup of measurement of a planar membrane humidifier operated in coflow. The measured operation characteristics including the measurement uncertainties for different NTU values compared with calculations are shown in figure 14.

\subsection{Crossflow}

Figure 15 shows the setup of measurement of a hollow fibre humidifier operated in crossflow unmixed on one side. $\dot{m}_{1}$ is unmixed and $\dot{m}_{2}$ is mixed. The measured operation characteristics including the measurement uncertainties for different NTU values compared with calculations are shown in figure 16.

Figures 12, 14 and 16 show that the calculated values are in good agreement with the experimental data. Table 4 shows the mean absolute percentage error and the maximum error for the three investigated flow configurations as well as respective values for the entirety of the measurement points. So, the fundamental properties of gas to gas humidifiers can be determined based on the presented method. Once these fundamental properties are known, the water exchange rate can be calculated. 


$$
\begin{aligned}
& \dot{m}_{1}^{\prime \prime}=\dot{m}_{1 \_ \text {Air }}^{\prime \prime}+\dot{m}_{1 \_H_{2} O}^{\prime \prime} \quad \dot{m}_{1}^{\prime}=\dot{m}_{1 \_ \text {Air }}^{\prime}+\dot{m}_{1_{-} H_{2} O}^{\prime}
\end{aligned}
$$

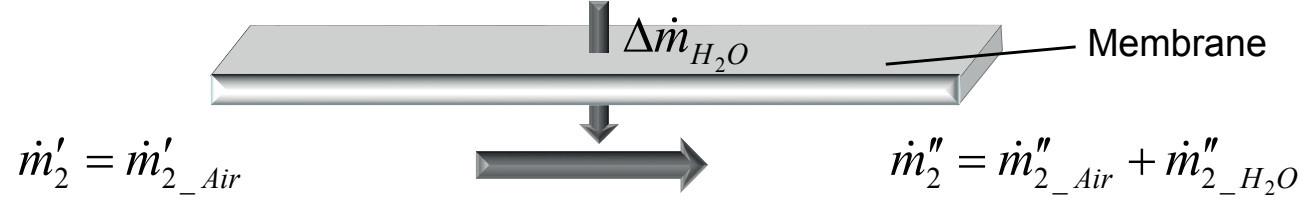

Figure 11: Setup measurement of operation characteristics for planar membrane humidifier in counterflow configuration

\begin{tabular}{lll}
\hline Flow configuration & Mean absolute percentage error & Maximum error \\
\hline Counterflow & $1.01 \%$ & $3.55 \%$ \\
Coflow & $2.37 \%$ & $7.10 \%$ \\
Crossflow & $0.58 \%$ & $1.80 \%$ \\
\hline Overall & $1.46 \%$ & $7.10 \%$ \\
\hline
\end{tabular}

Table 4: Comparison of the developed NTU-Model with experimental data in terms of mean absolute percentage error and maximum percentage error for the investigated flow configurations

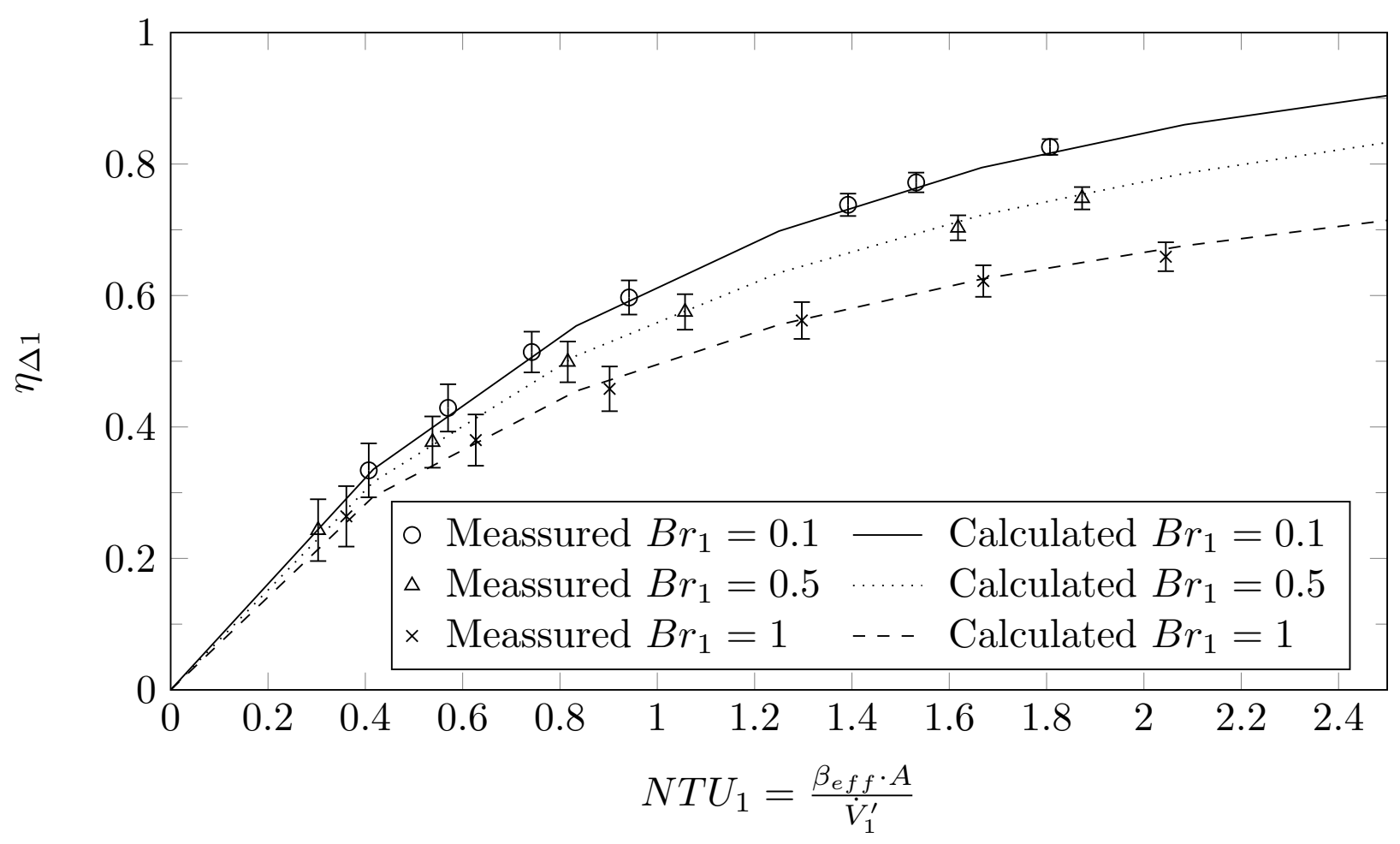

Figure 12: Measured and calculated operation characteristics for planar membrane humidifier in counterflow configuration 


$$
\begin{array}{lll}
\dot{m}_{1}^{\prime \prime}=\dot{m}_{1_{-} \text {Air }}^{\prime \prime}+\dot{m}_{1_{-} H_{2} O}^{\prime \prime} & \dot{m}_{1}^{\prime}=\dot{m}_{1_{-} \text {Air }}^{\prime}+\dot{m}_{1_{-} H_{2} O}^{\prime} \\
\dot{m}_{2}^{\prime \prime}=\dot{m}_{2 \text { Air }}^{\prime \prime}+\dot{m}_{2_{-} H_{2} O}^{\prime \prime} & \nabla \dot{m}_{H_{2} O} & \\
& \dot{m}_{2}^{\prime}=\dot{m}_{2_{-} \text {Air }}^{\prime}
\end{array}
$$

Figure 13: Setup measurement of operation characteristics for planar membrane humidifier in coflow configuration

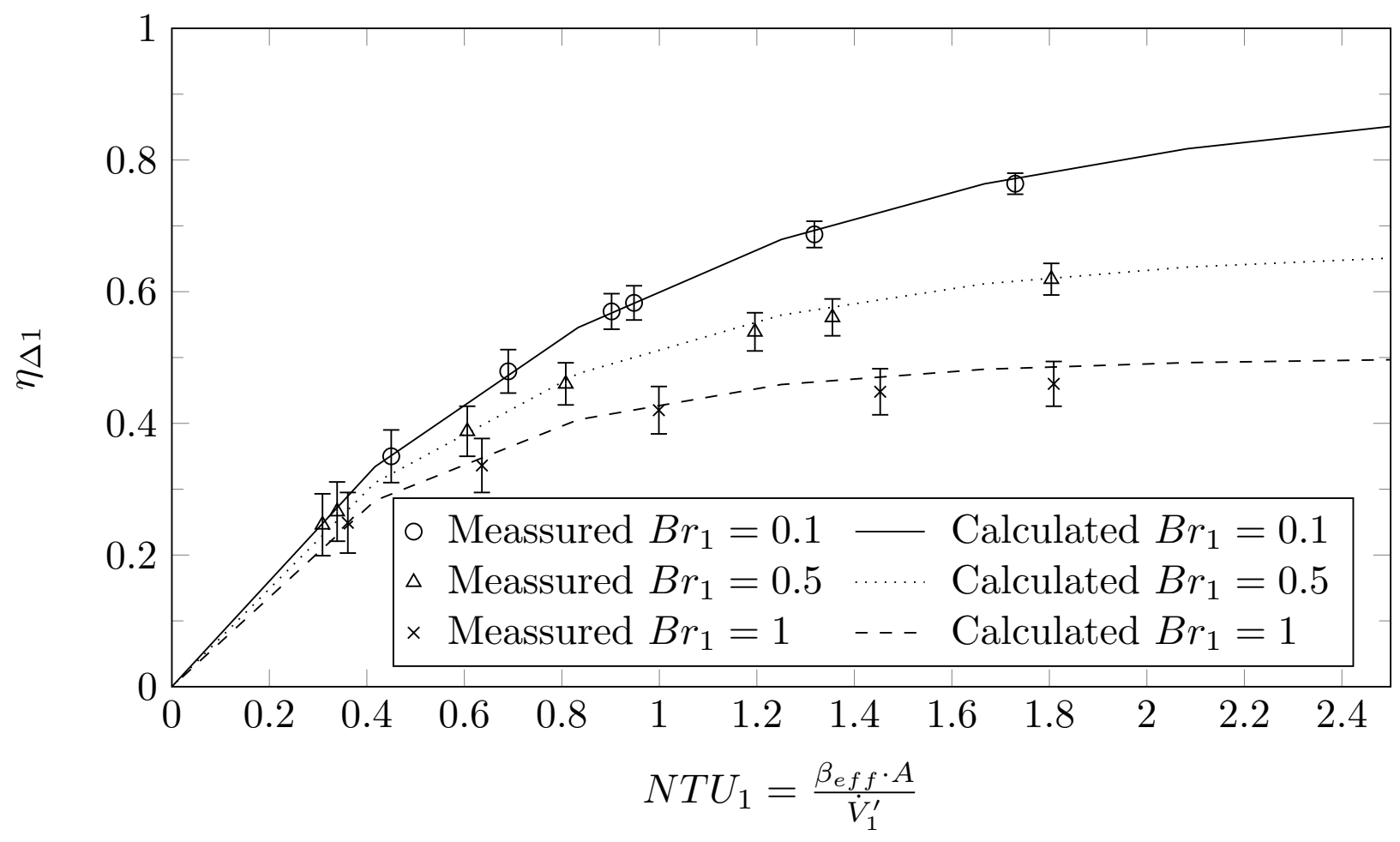

Figure 14: Measured and calculated operation characteristics for planar membrane humidifier in coflow configuration 


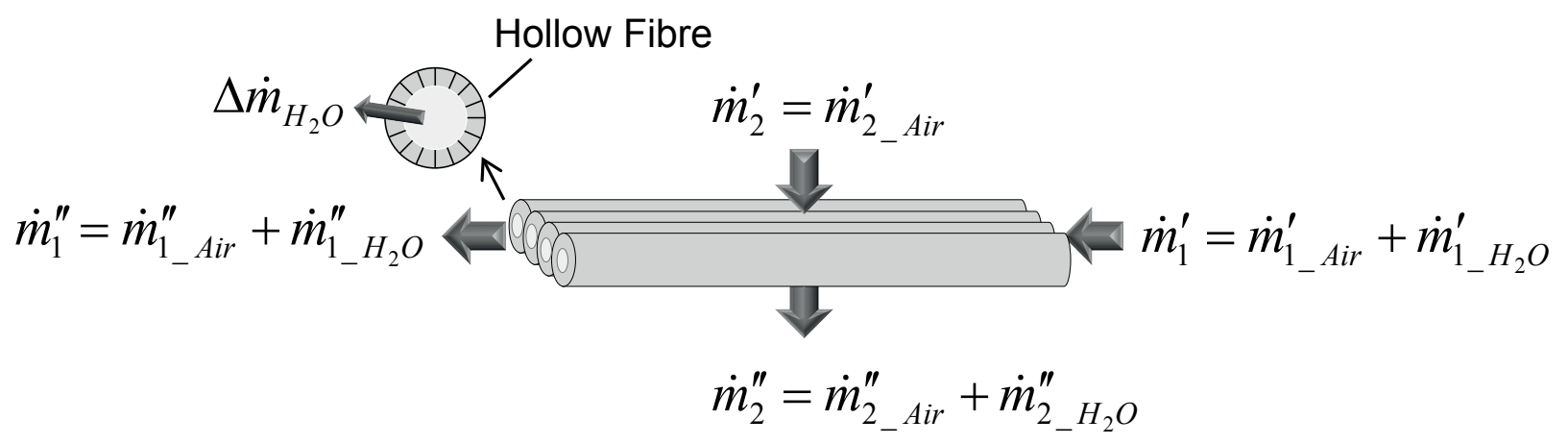

Figure 15: Setup Measurement of operation characteristics for hollow fibre humidifier in crossflow configuration (unmixed on one side)

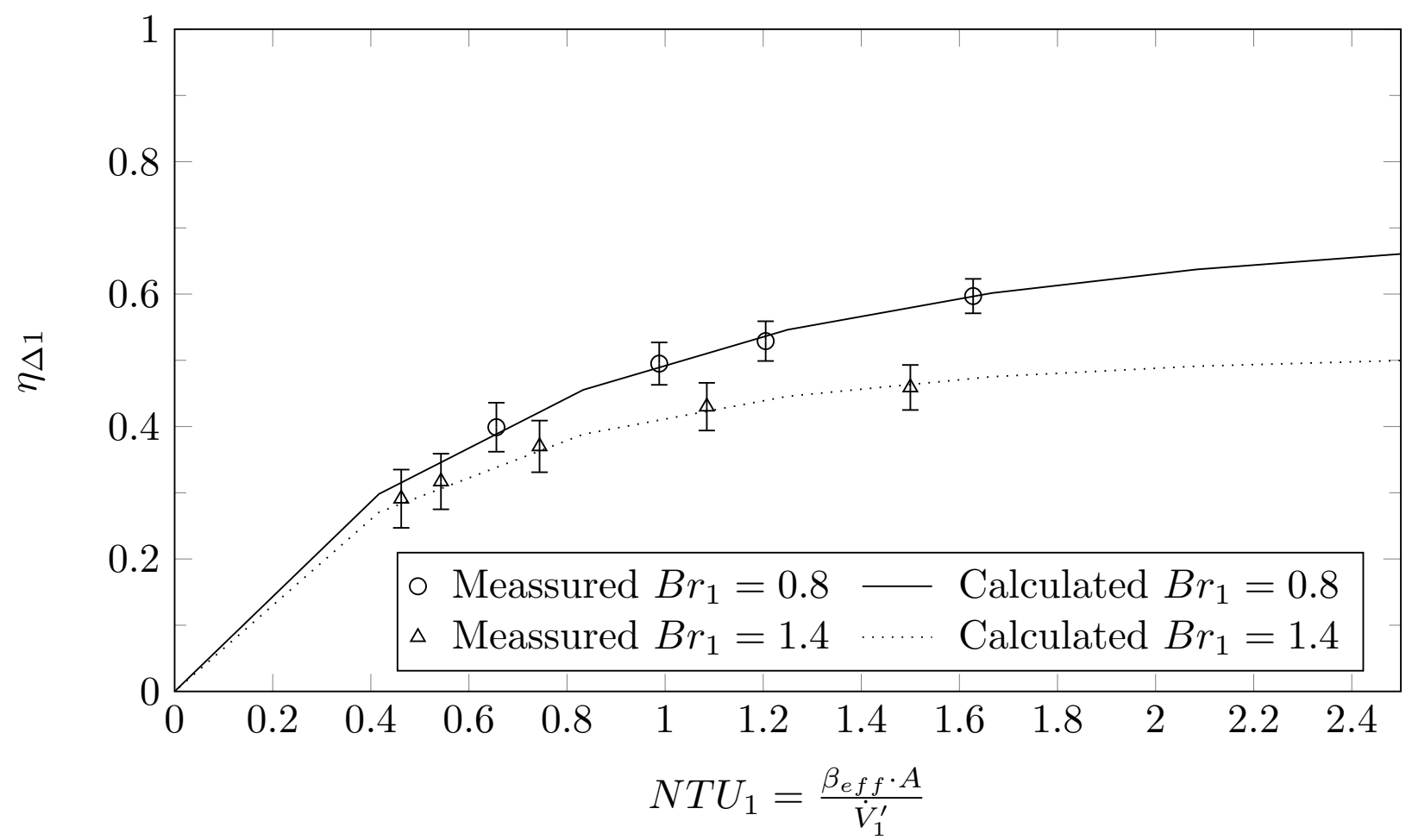

Figure 16: Measured and calculated operation characteristics for hollow fibre humidifier in crossflow configuration 


\section{Conclusion}

The NTU-Method is a well-established tool for analysing and designing heat exchangers. Based on the analogy of heat and mass transfer in the present work a similar method was developed for mass exchangers using three dimensionless numbers for the operation characteristics. The presented method is based on the assumption of negligible changes in overall volume and molar flow rates along the mass exchanger. This assumption is valid for the important application of air humidification of PEM fuel cells. The comparison of predicted and measured data of a gas humidifier for the three flow configurations coflow, counterflow and crossflow shows good agreement. The presented method can be used for analysing and designing mass exchangers (especially air humidifiers for fuel cells) as well as for controlling of mass exchange processes.

\section{References}

[1] H. Martin, Heat Exchangers, Hemisphere Publishing Corporation, Washington, 1992.

[2] H. D. Baehr, K. Stephan, Wärme- und Stoffübertragung, 8th Edition, Springer Berlin Heidelberg, 2013. doi:10.1007/ 978-3-642-36558-4.

[3] H. Hausen, Wärmeübertragung im Gegenstrom, Gleichstrom und Kreuzstrom, 2nd Edition, Springer Berlin Heidelberg, 1976.

[4] R. B. Bird, W. E. Stewart, E. N. Lightfoot, Transport Phenomena, Vol. 7, John Wiley and Sons, Inc., New York, 1960. doi:10.1002/aic.690070245.

[5] E.-U. Schlünder, Einführung in die Stoffübertragung, Georg Thieme Verlag, Stuttgart, 1984. doi:10.1002/star. 19850370213.

[6] E. Buckingham, On physically similar systems; Illustrations of the use of dimensional equations, Physical Review 4 (4) (1914) 345-376. doi:10.1103/PhysRev.4.345.

[7] R. Staek, Optimierung des Wasserhaushalts eines PEM-Brennstoffzellenaggregats, Ph.D. thesis, Technische Universität Braunschweig (2014).

[8] N. Brandau, Analyse zur Zellinternen Befeuchtung eines Polymerelektrolytmembran-Brennstoffzellenstapels, Logos Verlag, Berlin, 2013.

[9] N. Brandau, J. Köhler, Water Management in Proton Exchange Membrane Fuel Cells, In: C. Breitkopf, K. Swider-Lyons (Eds.), Springer Handbook of Electrochemical Energy, 1st Edition, Springer, Berlin Heidelberg, 2017.

[10] B. Weigand, J. Köhler, J. von Wolfersdorf, Thermodynamik kompakt, Springer-Lehrbuch, Springer Berlin Heidelberg, Berlin, Heidelberg, 2013. doi:10.1007/978-3-642-37233-9. 